\title{
Household income determines access to specialized pediatric chronic pain treatment in Germany
}

\author{
Ann-Kristin Ruhe ${ }^{*}$, Julia Wager ${ }^{1}$, Gerrit Hirschfeld ${ }^{2}$ and Boris Zernikow ${ }^{1}$
}

\begin{abstract}
Background: Families with lower socioeconomic status (SES) often face problems with gaining access to health care services. Information is scarce on the relationship between SES and health care delivery for children suffering from chronic pain.

Methods: Families presenting to a specialized pain center $(N=1,001)$ provided information on 'household income, 'parental education' and 'occupation' to aid the evaluation of their SES. To assess whether the SES of the clinical sample is representative of the general population, it was compared to data from a community sample $(N=14,558)$. For the clinical sample, travel distance to the clinic was described in relation to the $75 \%$ catchment area. Multiple logistic regression was used to analyze the association between SES and the journey from outside the catchment area.

Results: The SES was significantly higher in the clinical sample than in the community sample. Within the clinical sample, the distance traveled to the pain center increased with increasing SES. The $75 \%$ catchment area was 143 miles for families with the highest SES and 78 miles for the lowest SES. 'Household income' predicted travel distance (OR 1.32 (1.12-1.56)). Education and occupational status were not significant predictors of travel from outside the catchment area.

Conclusions: In Germany, specialized care for children with chronic pain is subject to disparities in access. Future activities should focus on identifying barriers to access and seeking to prevent inequalities in specialized pediatric health care delivery. Increasing the number of specialized treatment facilities could improve access to specialized pediatric pain treatment, regardless of socioeconomic determinants.
\end{abstract}

Keywords: Socioeconomic status (SES), Pediatric, Chronic pain, Health care delivery, Income, Inequality, Specialized treatment

\section{Background}

One important goal of developed societies is that every citizen has access to good health care [1-3]. However, barriers to health care access exist. They range from regionally reduced availability of services (i.e., travel distances $[4,5]$ ) and unaffordable treatment costs to a lack of information about treatment options [6].

\footnotetext{
* Correspondence: a.ruhe@deutsches-kinderschmerzzentrum.de

'German Paediatric Pain Centre, Children's and Adolescents' Hospital,

Datteln, and Department of Children's Pain Therapy and Paediatric Palliative

Care, Witten/Herdecke University, Faculty of Health - School of Medicine,

Dr.-Friedrich-Steiner-Str .5, 45711 Datteln, Germany

Full list of author information is available at the end of the article
}

Irrespective of the health care system, children already experience inequalities in health care use due to social differences and poverty. For example, German families with a lower socioeconomic status (SES) consult health care specialists, like pediatricians, ophthalmologists and dermatologists, less often than families with a higher SES [7]. In the US, children from families with lower household income in particular seem to have difficulties in accessing specialized care $[8,9]$. Children with chronic health complaints also experience these social inequalities in different health care systems $[6,10,11]$.

Comparability across studies dealing with the role of SES in health care utilization is generally hampered due 
to differences in sample characteristics, health care systems (i.e., type of regulation, service provision and financing [12]) or SES measures [13]. Studies often do not apply a comprehensive measure of SES that includes household income, parental education and occupation [5, 14-19].

In children, chronic pain is a major health care problem [20] that requires treatment to interrupt chronification [21]. However, it often takes a long time for these children to reach a specialized care center [22]. To our knowledge, only one study thus far has investigated the possible effects of SES on health service use in children with chronic pain [5]. This German study showed that children of parents with a higher occupational skill level traveled longer distances to receive specialized pain treatment [5]. Other socioeconomic factors were not investigated in this study. In adult chronic pain patients, few studies have analyzed the determinants of health care use. These showed that access to health care is associated with higher socioeconomic factors such as income or education [23, 24].

The aim of this study is to explore the effect of SES on health care utilization at a specialized pediatric pain center in Germany. SES was measured as a multidimensional construct including 'household income,' 'parental education' and 'parental occupation'. This measure has previously been applied by a German community survey $[25,26]$. The current study specifically investigated the following aspects: 1) comparability of the SES between a clinical pain sample and a community sample; 2) the association between SES and distance traveled to a specialized pediatric pain center; 3 ) the impact of single socioeconomic parameters on the distance traveled to a specialized pediatric pain center in Germany.

\section{Methods}

\section{Data sources}

We analyzed data from two samples of German children and adolescents aged between 3 and 17 years: a community sample $(N=14,558)$ and a clinical sample $(N=1,001)$ from a specialized pediatric pain clinic.

The community sample comprises a representative study sample from the German Health Interview and Examination Survey for Children and Adolescents (KiGGS), conducted by the German Robert Koch Institute (RKI) from May 2003 to May 2006. A Public Use File of the KiGGS-data is available at the RKI. Data on SES were missing for 278 subjects (drop-out rate: $1.9 \%$ ). In the community sample, half of the children (51\%) were male, and the mean age was 10 years $(\mathrm{SD}=4.2)$. A detailed description of the sample and the study design has been provided elsewhere [27-29].

The clinical sample comprises children and adolescents who sought treatment at the German Paediatric Pain
Centre (GPPC) between August 1, 2012, and March 31, 2014 (a period of 18 months). Of the original 1037 patients, 30 families did not fill out the SES questionnaire and 6 children were excluded because they reported living in an institution or with relatives, making assessment of parental SES unfeasible (drop-out rate: $3.5 \%$ ). The majority of the 1001 children in the clinical sample were female (67\%), and the mean age was 13 years (SD 2.9). The most frequent main pain locations were the head (58 \%), back/ extremities $(26 \%)$ and abdomen (24\%).

\section{Measures}

In the community sample, adolescents aged between 11 and 17 years completed their own questionnaire of pain items. For those under the age of 11, parents answered the questions [28]. We extracted basic demographic information (e.g., age, sex) and information on the pain problem: any pain during the previous three months, recurrent pain (i.e., pain that occurs at least once in a month for more than the previous three months) and $\geq 1$ physician contact, i.e., children and adolescents who reported at least one physician contact due to their recurrent pain problem. SES was measured on the basis of parental information regarding their education and vocational training, their occupational situation and the household income per month, by means of a standardized questionnaire. The respective level of these three single parameters was categorized by the assignment of value points ranging from 1 (lowest level) to 7 (highest level). Using this information, the SES could be operationalized into a multidimensional status index called the Winkler Index, which is a continuous measure (scale range 3-21) [26]. A detailed description of level operationalization has been published [30]. If information on education and occupation was available for both parents, the highest level provided was used to define parental education and occupation. Additionally, the socioeconomic status level was divided into three status groups: low (range 3-8), medium (range 9-14) and high (15-21) [30].

In the clinical sample, a battery of questionnaires was completed prior to the first appointment. In adolescents aged 11 years and older, information on the pain issue was measured by self-report, while the information was gained by parent proxy report for children younger than 11 years of age. For the clinical sample, the following data were collected: basic demographic information (e.g., age, sex, place of residence), information on the pain issue (e.g., pain intensity and frequency, pain-related school absence and disability and main pain location head, abdomen, back/extremities]), as well as the number of physicians/ therapists' consultations during the past three months. The impairment level (extremely high vs. high) was determined by means of predefined indicators for intensive inpatient pain treatment [22]. Children had to fulfill three of the 
following five criteria to be considered extremely highly impaired:

- pain duration $\geq 6$ months,

- constant pain with an average pain intensity of $\mathrm{NRS} \geq 5$,

- pain peaks of NRS $\geq 8$,

- at least 5 days of absence from school within the preceding 4 weeks

- high pain disability (P-PDI $\geq 36$ ) [31-33].

In the clinical sample, parents also reported on their own education and vocational training, their occupational situation and the household income per month, and these factors were used to calculate the Winkler Index [26].

In the present study, access refers to the actual usage of a specialized pediatric pain clinic. It was measured by means of travel distance (in miles and kilometers). Travel distance to the clinic was determined based on the patients' zip codes and calculated using Google Maps. Travel distance was described in relation to the $75 \%$ catchment area, i.e., the area that included $75 \%$ of the patients [34]. In addition, parents reported on their means of transportation (i.e., car, motorcycle, bicycle, public transport, taxi, or on foot).

\section{Ethics}

The Ethics committee of the Children's Hospital in Datteln, Germany, approved the study. At the time of the initial presentation, all families gave written informed consent for data collection, electronic storage and data analysis.

\section{Statistical methods}

Patient characteristics, socioeconomic status and travel distance were presented using descriptive statistics including frequencies, means, and standard deviations [SDs]. The socioeconomic differences between the community and the clinical sample were tested with Student's t-test (for the Winkler Index) and the MannWhitney-U test (for the three SES status groups household income, parental education and occupation). Effect sizes were calculated and interpreted according to established standards [35].

To test the association between SES and travel distance in the clinical sample, we performed two different analyses. First, we calculated the differences in the $75 \%$ catchment area between SES status groups. The $95 \%$ confidence intervals (CI) were generated using bootstrapping (with 1000 replications). Second, a multiple logistic regression model calculated the Odds Ratio (OR) (of the Winkler Index) for coming from outside the $75 \%$ catchment area. Control variables were included based on previous research [5] as follows: the child's age, sex, impairment level (extremely high vs. high impairment), the main pain location (head, abdomen or back/ extremities), and the number of physicians/therapists' consultations during the past three months (as a continuous variable). To allow comparisons across regression coefficients, the three continuous variables 'age', 'number of consultations' and the 'Winkler Index' were standardized, i.e., divided by twice the SD [36]. The relative contribution of each factor associated with high travel distance was quantified as an OR with a $95 \% \mathrm{CI}$. The significance level was set at $p<0.05$.

To work out the sole impact of the three single socioeconomic parameters of the Winkler Index, a multivariate logistic regression model was constructed, including income (seven income groups), educational level (seven categories with value points from 1 to 7) and occupational status (seven categories with value points from 1 to 7). The influencing factors mentioned above were included in the logistic regression model.

All analyses were performed using SPSS Version 22.0.

\section{Results}

Socioeconomic status - community versus clinical sample In the community sample, one-quarter of the families (26\%) reported a high SES compared with nearly one-half (45\%) in the clinical sample. More families in the community sample had low SES (28\%) compared with the clinical sample (10\%). Accordingly, the mean SES in the clinical sample was significantly higher (Winkler Index: 13.9 versus 11.5). The strength of the socioeconomic difference between the clinical sample and the community sample was high (Cohen's d: 0.6) [35] (Table 1).

The analyses comparing the pain subgroups in the community sample with the clinical sample regarding socioeconomic differences revealed similar results: Irrespective of whether children in the community sample reported any pain or recurrent pain and whether they had previous physician contact due to pain, the mean SES in the clinical sample was significantly higher (Table 1).

The distribution of the three single socioeconomic parameters revealed that parents within the clinical sample had higher educational and occupational levels as well as household income compared with the parents in the community sample $(p<0.001)$ (Fig. 1).

\section{Socioeconomic status and its association with travel distance (in the clinical sample)}

Families in the clinical sample traveled an average of 86 miles (range: 1.5 - 434 miles), or $138 \mathrm{~km}$ (range: 2.3 $698 \mathrm{~km})$, to the GPPC. The $75 \%$ catchment area spanned 121 miles $(195 \mathrm{~km})$. Most families (95 \%) traveled by car.

A significant association was found between SES and distance traveled $(p<0.001)$, with the higher SES status 
Table 1 Socioeconomic status in the community and the clinical sample

\begin{tabular}{|c|c|c|c|c|c|}
\hline & \multirow{2}{*}{$\begin{array}{l}\text { Clinical Sample } \\
\text { All }\end{array}$} & \multicolumn{4}{|c|}{ Community Sample } \\
\hline & & All & Children with any pain ${ }^{a}$ & $\begin{array}{l}\text { Children with recurrent } \\
\text { pain }^{b}\end{array}$ & $\begin{array}{l}\text { Children with } \geq 1 \text { physician } \\
\text { contact due to recurrent pain }\end{array}$ \\
\hline & $n=979$ & $n=14,455$ & $n=9901$ & $n=3340$ & $n=2244$ \\
\hline \multicolumn{6}{|c|}{ Winkler-Index (range 3 - 21) } \\
\hline Mean & 13.9 & 11.5 & 11.5 & 11.5 & 11.1 \\
\hline SD & 4.1 & 4.3 & 4.3 & 4.3 & 4.2 \\
\hline Mean difference & & $-2.5^{* * *}$ & $-2.4^{* * *}$ & $-2.4^{* * *}$ & $-2.8^{* * *}$ \\
\hline Effect Size (Cohen's d) & & 0.6 & 0.6 & 0.6 & 0.7 \\
\hline \multicolumn{6}{|l|}{ SES status group } \\
\hline Low $(3-8)$ & $9.7 \%$ & $27.5 \%$ & $26.9 \%$ & $26.3 \%$ & $29.5 \%$ \\
\hline Medium $(9-14)$ & $45.5 \%$ & $46.9 \%$ & $47.4 \%$ & $48.3 \%$ & $48.4 \%$ \\
\hline High $(15-21)$ & $44.8 \%$ & $25.6 \%$ & $25.7 \%$ & $25.4 \%$ & $22.2 \%$ \\
\hline$p^{\#}$ & & $<0.001$ & $<0.001$ & $<0.001$ & $<0.001$ \\
\hline
\end{tabular}

comparisons were calculated for all subgroups of the community sample with the clinical sample

${ }^{* * *} p<0.001$ (Student's t-test). ${ }^{*} p$-value for Mann-Whitney-U test

${ }^{\text {aAny }}$ pain: children and adolescents reporting any pain during the last three months

${ }^{\mathrm{b}}$ Recurrent pain: children and adolescents reporting recurrent pain, i.e., pain that occurs at least once in a month for more than the previous three months

$c_{\geq 1}$ Physician contact due to recurrent pain: children and adolescents who reported at least one physician contact due to their recurrent pain problem

group (based on the Winkler Index) traveling a longer distance to the clinic.

The $75 \%$ catchment areas for families with low and medium socioeconomic status were 78 miles $(95 \% \mathrm{CI}$ : 46.2-130.0), or $125 \mathrm{~km}$, and 100 miles (95 \% CI: 90.9$123.0)$, or $161 \mathrm{~km}$, respectively. Families with a high socioeconomic status had a $75 \%$ catchment area of 143 miles (95 \% CI: 125.8-162.6), or 231 km (Fig. 2).

The logistic regression model revealed that families were more likely to come from outside the $75 \%$ catchment area $(>121$ miles) as their socioeconomic status increased (OR $1.79(1.2-2.68)$ ). In considering the three single parameters of SES within multiple logistic regression, the families' household income was the only factor that was significantly associated with travel distance, i.e., with increasing household income, the probability of coming from outside the catchment area increased (OR 1.32 (1.12-1.56)). Parental education and occupational status had no significant effect (OR 0.94 (0.79-1.12) and OR $1.01(0.86-1.21)$, respectively).

Accordingly, the $75 \%$ catchment area for families with a household income up to 2249 Euro per month was only 92 miles (95 \% CI: 71.1-125.9), or 148 km. Families with a household income between 2250 Euro and 3999 Euro per month had a $75 \%$ catchment area of 113 miles (95\% CI 95.3-130.0), or $182 \mathrm{~km}$, and those with a household income over 4000 Euro per month had a 75 \% catchment area of 153 miles (95\% CI 135.6-189.9), or $246 \mathrm{~km}$.

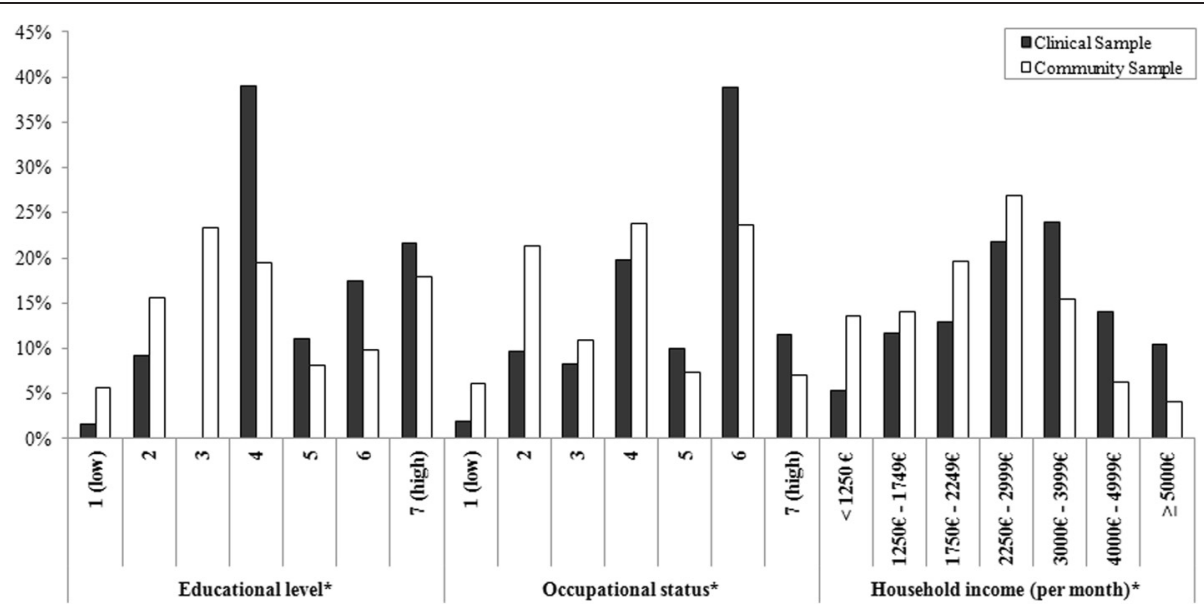

Fig. 1 Distribution of socioeconomic parameters. *Differences between the clinical and the community sample were statistically significant with $p<0.001$ (Mann-Whitney-U test) 


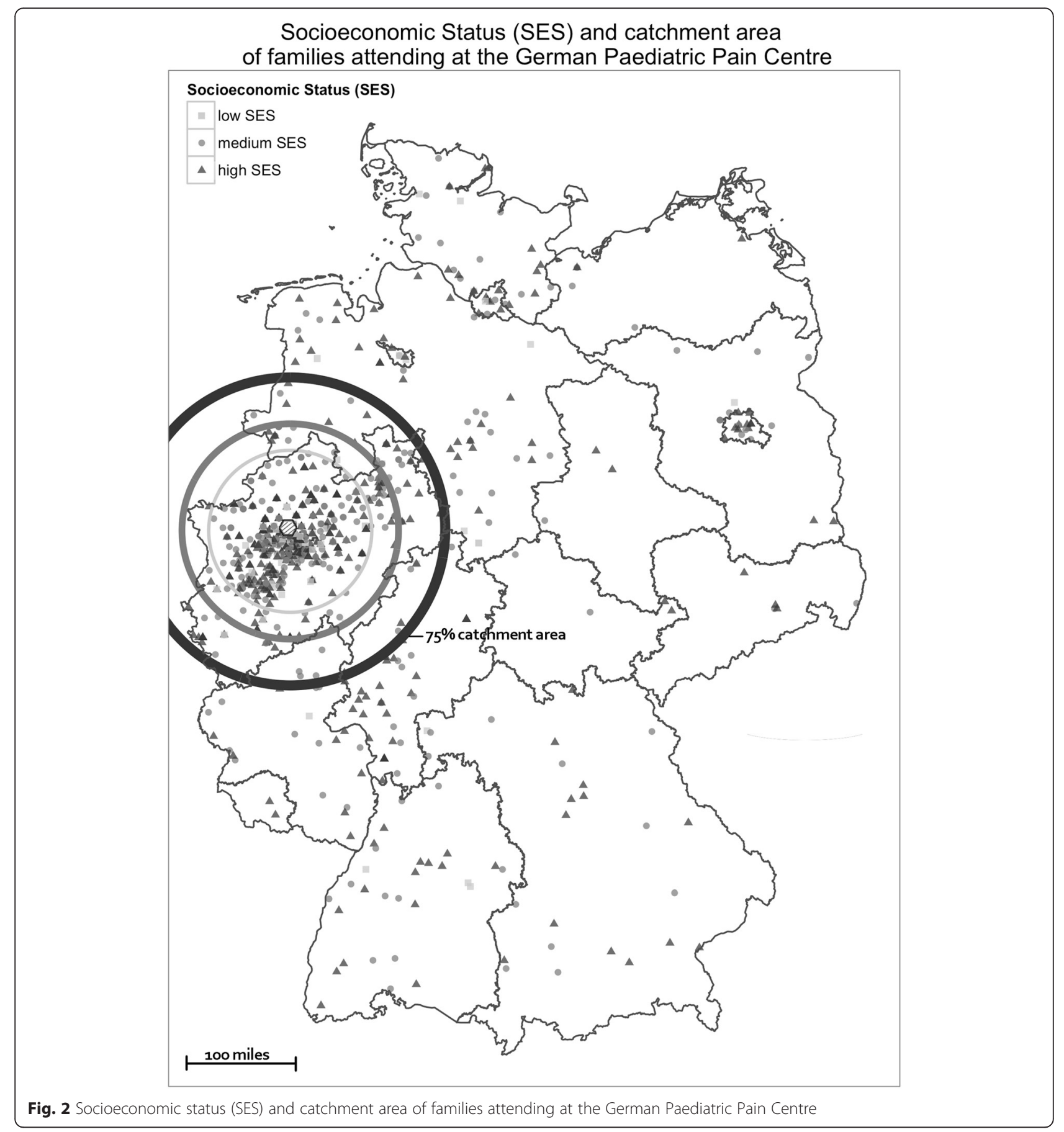

\section{Discussion}

Children seeking a specialized pediatric pain clinic have a higher SES compared with a community sample. Within the clinical sample, children of parents with a higher SES traveled longer distances to the pain clinic than did children of parents with a lower SES. The $75 \%$ catchment area for families with a low SES amounted to almost half (78 miles) the distance in the high SES group (143 miles).
Of the three single socioeconomic parameters, income has the single most significant association with travel distance.

In line with the results of the current study, previous studies in children and adults have revealed that low SES is a barrier for health care utilization (see Additional file 1: Table S1 and Additional file 2: Table S2). Different reasons for this situation have been proposed. In some countries, not all children and their families have health 
insurance, and there can also be financial gaps in private or public programs that may influence the use of health care services or access, especially among low-income families [37]. Furthermore, a lack of information can be a barrier to accessing health care [6], especially in countries without institutionalized gate keeping systems, such as Germany, where patients can decide themselves which physician they wish to consult. Finally, barriers for patients with chronic pain may include limitations in the availability of services [38, 39].

The results of the present study showed that the combined measure of the Winkler-Index has a stronger association with travel distance than the three single parameters of the SES. Accordingly, the combined measure seems to be the most validated and reliable representation of the overall construct of SES.

The present study also depicted the individual effects of income, parental education and occupation. Surprisingly, only income, not educational or occupational status, showed a significant association with the distance traveled. In Germany, people are generally obliged to obtain state or private health insurance coverage. Only $0.2 \%$ of the German working population lacks health insurance. Usually children are covered under their parents' insurance [40] and the insurant is eligible for free health care services for disease prevention and treatment [41], including specialized pain therapy. These results suggest that children of parents with a lower income face significant barriers to accessing appropriate care. Because health insurance covers treatment costs, the financial situation of the family seems to determine whether they can afford the journey to the pain center, which is not covered by their health insurance.

Importantly, interpretations of the results need to take into account the socioeconomic imbalance between the community and the clinical sample. SES in the clinical sample is not representative of the entire German population. Those families presenting at the specialized pain clinic report higher educational and occupational levels, as well as disposable income. Those families with a low social status in particular are underrepresented. Therefore, any striking differences within the clinical group might not be obvious, as the SES level is quite high within this group. In consideration of this selection bias, it is not clear whether education and occupational status may play a role among the population in general and whether the income gradient is even greater.

Due to the higher SES in the clinical sample, it could be assumed that severe chronic pain is more prevalent with increasing SES. Current studies, however, provide no evidence that the socioeconomic level is a predictor for the development of chronic pain [42-44]. Thus, there seems to be no increased demand (i.e., greater disease severity or prevalence) in some status groups that could explain the greater effort higher status groups make in terms of traveling longer distances. For families with a lower SES in particular, the insufficient supply of specialized pediatric pain services seems to have a negative impact on access.

\section{Strengths of this study}

Information on SES has been collected from a large number of families visiting a specialized pain clinic. To our knowledge, there is no comparable study in the literature that analyzes the effect of SES on health care utilization in such a large pediatric chronic pain sample. The drop-out rate within this study is very low, which allows for good generalizability for similar institutions. Furthermore, this low drop-out rate shows that parents are willing to provide sensitive information for the sake of a research project that may lead to benefits for patients.

This study operationalized SES for the purposes of an epidemiological study. A frequent problem with tertiary care research is the lack of comparability with the general population. This approach allowed us to compare clinical data with general population data.

\section{Limitations}

There are some limitations that must be kept in mind when interpreting the present findings.

First, it is important to note that health care utilization is influenced by supply and (individual or community) demand [45]. Hence, the association between SES and health service utilization is more complex than the present study implies. There are further potential factors beyond SES and those influencing variables that were controlled for that may influence a patient's decision to seek treatment, including the quality and type of care, as well as time resources [46, 47] and the willingness to seek treatment [45]. It could be that further influencing factors such as lifestyle and living conditions need to be taken into account to evaluate the unequal distribution of health risks and healthrelated opportunities [48]. Second, in this study, we used travel distance calculated by zip codes as a measure of access. This, however, is only one possible criterion to describe access. An alternative measure could be travel burden, costs or actual travel time. The use of zip codes to calculate travel distance furthermore failed to take into account the actual travel distance. It only represents a rough estimate. A more precise determination would require the family's full address.

Third, data from the clinical sample only offer information on those children and adolescents seeking treatment at the German Paediatric Pain Centre. This clinic is unique in Germany, offering inpatient treatment on a ward solely for chronic pain. However, this study does not capture data from children and adolescents suffering from chronic pain who have a need for specialized treatment but who fail to reach appropriate care due to socioeconomic barriers, 
undersupply or other influencing factors. The closest we could get to this group was by comparing the clinical sample with those children from the general population seeking care due to recurrent pain.

Finally, results of the present study cannot be generalized to all countries, because they highly depend on the health care system and the availability of services.

\section{Conclusion}

The results of the present study suggest that German children and adolescents suffering from chronic pain are subject to disparities in access to specialized health care. Within the clinical sample, children from high-income families were much more likely to come from afar. The large catchment area may indicate inadequate resources in other regions. Therefore, if the long travel distances and subsequent costs are the main problem, providing a greater number of treatment facilities could be one way to enhance health care delivery for children and adolescents with chronic pain. Future research needs to examine the gaps in the knowledge base with regards to barriers to care, especially the broader patterns of socioeconomic factors and their association with resource utilization in the general population. A better understanding of the patterns of socioeconomic gradients in children's health could identify vulnerable groups and inform policy in terms of barriers to equal delivery and access. This knowledge may form the basis for the development of measures that may be protective and supportive for socially disadvantaged children and their families.

\section{Additional files}

Additional file 1: Table S1. Socioeconomic status and access to health care services (studies in children and adolescents) [5, 6, 8-11, 49-51]. (DOC $52 \mathrm{~kb}$ )

Additional file 2: Table S2. Socioeconomic status and access to health care services in adult chronic pain patients [23, 24, 52]. (DOC 37 kb)

\section{Abbreviations \\ Cl: confidence interval; SES: socioeconomic status; GPPC: German Paediatric Pain Centre; KiGGS: German Health Interview and Examination Survey for Children and Adolescent; km: kilometer; NRS: numeric rating scale; OR: odds ratio; P-PDI: pediatric pain disability index; RKI: Robert Koch Institute; \\ SD: standard deviation.}

\section{Competing interests}

The authors declare that they have no competing interests.

\section{Authors' contributions}

$A R, J W$ and BZ were responsible for the conception and design of the study, as well as for interpretation of the results and the drafting and revising of the paper. AR carried out the data collection and data management of the study. JW and AR contributed to the data analysis. JW, GH and AR contributed to the conception of the tables and figures. All the authors discussed the results and commented on the manuscript. All authors read and approved the final manuscript.

\section{Acknowledgements}

The authors declare that no funding sources were provided.

\section{Author details}

${ }^{1}$ German Paediatric Pain Centre, Children's and Adolescents' Hospital, Datteln, and Department of Children's Pain Therapy and Paediatric Palliative Care, Witten/Herdecke University, Faculty of Health - School of Medicine, Dr.-Friedrich-Steiner-Str .5, 45711 Datteln, Germany. ${ }^{2}$ Faculty of Economics and Social Sciences, University of Applied Sciences Osnabrück, Caprivistr. 30A, 49076 Osnabrück, Germany.

Received: 21 January 2015 Accepted: 18 April 2016

Published online: 21 April 2016

\section{References}

1. Apouey B, Geoffard PY. Family income and child health in the UK. J Health Econ. 2013;32(4):715-27.

2. Social Code Book V: Social Code Book V - Statutory Health Insurance, § 27 Hospital treatment. 2014. http://www.gesetze-im-internet.de/sgb_5/. [Accessed 20 Apr 2016].

3. Obama B: Fact Sheet: Global Health Security. President Obama's Address to the United Nations General Assembly, September 22, 2011. The White House 2011. www.whitehouse.gov/the-pressoffice/2011/09/22/fact-sheetglobal-health-security. [Accessed 20 April 2016].

4. Yantzi N, Rosenberg MW, Burke SO, Harrison MB. The impacts of distance to hospital on families with a child with a chronic condition. Soc Sci Med. 2001;52(12):1777-91

5. Wager J, Ruhe A, Hirschfeld G, Wamsler C, Dobe M, Hechler T, Zernikow B. Influence of parental occupation on access to specialised treatment for paediatric chronic pain: A retrospective study. Schmerz. 2013;27(3):305-11.

6. Valenzuela JM, Seid M, Waitzfelder B, Anderson AM, Beavers DP, Dabelea DM, Dolan LM, Imperatore G, Marcovina S, Reynolds K. Prevalence of and Disparities in Barriers to Care Experienced by Youth with Type 1 Diabetes. J Pediatr. 2014;164(6):1369-75.

7. Kamtsiuris P, Bergmann E, Rattay P, Schlaud M. [Use of medical services. Results of the German Health Interview and Examination Survey for Children and Adolescents (KiGGS)]. Bundesgesundheitsblatt Gesundheitsforschung Gesundheitsschutz. 2007;50(5-6):836-50.

8. Larson K, Halfon N. Family income gradients in the health and health care access of US children. Matern Child Health J. 2010;14(3):332-42.

9. Kuhlthau K, Nyman RM, Ferris TG, Beal AC, Perrin JM. Correlates of use of specialty care. Pediatr. 2004;113(3):e249-55.

10. Amone-P'Olak K, Ormel J, Oldehinkel AJ, Reijneveld SA, Verhulst FC, Burger $\mathrm{H}$. Socioeconomic position predicts specialty mental health service use independent of clinical severity: The TRAILS study. J Am Acad Child Adolesc Psychiatry. 2010;49(7):647-55.

11. Kemper KJ, Gardiner P, Birdee GS. Use of Complementary and Alternative Medical Therapies Among Youth With Mental Health Concerns. Acad Ped. 2013;13(6):540-5.

12. Simon M. Das Gesundheitssystem in Deutschland. Eine Einführung in Struktur und Funktionsweise, Vol. 4. Bern: Hans Huber; 2008.

13. Reiss F. Socioeconomic inequalities and mental health problems in children and adolescents: a systematic review. Soc Sci Med. 2013;90:24-31.

14. Howe LD, Lawlor DA, Propper C. Trajectories of socioeconomic inequalities in health, behaviours and academic achievement across childhood and adolescence. J Epidemiol Community Health. 2013;67:358-64.

15. Jarrin DC, McGrath JJ, Quon EC. Objective and subjective socioeconomic gradients exist for sleep in children and adolescents. Health Psychol. 2014; 33(3):301-5.

16. Schechter MS, McColley SA, Silva S, Haselkorn T, Konstan MW, Wagener JS. Association of socioeconomic status with the use of chronic therapies and healthcare utilization in children with cystic fibrosis. J Pediatr. 2009;155(5):634-9.

17. Koivusilta LK, Rimpel AH, Kautiainen SM. Health inequality in adolescence. Does stratification occur by familial social background, family affluence, or personal social position? BMC Public Health. 2006;6(1):110-22.

18. Toliver-Sokol M, Murray CB, Wilson AC, Lewandowski A, Palermo TM. Patterns and predictors of health service utilization in adolescents with pain: Comparison between a community and a clinical pain sample. J Pain. 2011;12(7):747-55. 
19. Wichstrom L, Belsky J, Jozefiak T, Sourander A, Berg-Nielsen TS. Predicting Service Use for Mental Health Problems Among Young Children. Pediatr. 2014;133(6):1054-60.

20. King S, Chambers CT, Huguet A, MacNevin RC, McGrath PJ, Parker L, MacDonald AJ. The epidemiology of chronic pain in children and adolescents revisited: A systematic review. Pain. 2011;152(12):2729-38.

21. Hechler T, Ruhe A-K, Schmidt P, Hirsch J, Wager J, Dobe M, Krummenauer F, Zernikow B. Inpatient-based intensive interdisciplinary pain treatment for highly impaired children with severe chronic pain: randomized controlled trial of efficacy and economic effects. Pain. 2014;155(1):118-28.

22. Zernikow B, Wager J, Hechler T, Hasan C, Rohr U, Dobe M, Meyer A, Hübner-Möhler B, Wamsler C, Blankenburg M. Characteristics of highly impaired children with severe chronic pain: A 5-year retrospective study on 2249 pediatric pain patients. BMC Pediatr. 2012;16(12):54-65.

23. Azevedo LF, Costa-Pereira A, Mendonca L, Dias CC, Castro-Lopes J. Chronic Pain and Health Services Utilization: Is There Overuse of Diagnostic Tests and Inequalities in Nonpharmacologic Treatment Methods Utilization? Med Care. 2013;51(10):859-69.

24. Rahman MM, Kopec JA, Sayre EC, Greidanus NV, Aghajanian J, Anis AH, Cibere J, Jordan JM, Badley EM. Effect of sociodemographic factors on surgical consultations and hip or knee replacements among patients with osteoarthritis in British Columbia, Canada. J Rheumatol. 2011;38(3):503-9.

25. Lampert T, Schenk L, Stolzenberg H. [Conceptualization and operationalization of social inequality in The Child and Adolescent Health Survey]. Gesundheitsw. 2002;64:48-52.

26. Lampert T, Kroll LE. Die Messung des sozioökonomischen Status in sozialepidemiologischen Studien. In: Gesundheitliche Ungleichheit. edn.: VS Verlag für Sozialwissenschaften; 2009: 309-334.

27. Hölling H, Schlack R, Kamtsiuris P, Butschalowsky H, Schlaud M, Kurth BM. [The KiGGS study. Nationwide representative longitudinal and cross-sectional study on the health of children and adolescents within the framework of health monitoring at the Robert Koch Institute]. Bundesgesundheitsblatt Gesundheitsforschung Gesundheitsschutz. 2012;55(6-7):836-42.

28. Kurth BM, Bergmann KE, Hölling $H$, Kahl $H$, Kamtsiuris $P$, Thefeld W. The National Child and Adolescent Health Survey. The complete concept. Gesundheitswesen. 2002:64:3-11.

29. Ellert U, Neuhauser $H$, Roth-Isigkeit A. [Pain in children and adolescents in Germany: the prevalence and usage of medical services. Results of the German Health Interview and Examination Survey for Children and Adolescents (KiGGS)]. Bundesgesundheitsblatt Gesundheitsforschung Gesundheitsschutz. 2007:50(5-6):711-7.

30. Lange M, Kamtsiuris P, Lange C, Schaffrath Rosario A, Stolzenberg H, Lampert T. [Sociodemographic characteristics in the German Health Interview and Examination Survey for Children and Adolescents (KiGGS) operationalisation and public health significance, taking as an example the assessment of general state of health]. Bundesgesundheitsblatt Gesundheitsforschung Gesundheitsschutz. 2007:50:578-89.

31. Dobe M, Damschen U, Reiffer-Wiesel B, Sauer C, Zernikow B. Three-week multimodal inpatient treatment of children with chronic pain. First results of the long-term follow-up. Schmerz. 2006;20(1):51-60.

32. Hechler T, Dobe M, Kosfelder J, Damschen U, Hübner B, Blankenburg M, Sauer C, Zernikow B. Effectiveness of a three-week multimodal inpatient pain treatment for adolescents suffering from chronic pain: Statistical and clinical significance. Clin J Pain. 2009;25(2):156-66.

33. Zernikow B, Dobe M, Hirschfeld G, Blankenburg M, Reuther M, Maier C. [Please don't hurt me!: a plea against invasive procedures in children and adolescents with complex regional pain syndrome (CRPS)]. Schmerz. 2012;26(4):389-95.

34. Chou SY, Deily ME, Li S. Hospital Report Cards, Patients' Travel Distance, and Health Outcomes. 2009.

35. Cohen J. Statistical power analysis for the behavioral sciences. New Jersey: Lawrence Earlbaum Associates; 1988.

36. Gelman A. Scaling regression inputs by dividing by two standard deviations. Stat Med. 2008;27(15):2865-73.

37. Simpson L, Owens PL, Zodet MW, Chevarley FM, Dougherty D, Elixhauser A, McCormick MC. Health care for children and youth in the United States: annual report on patterns of coverage, utilization, quality, and expenditures by income. Ambul Pediatr. 2005;5(1):6-e20.

38. Hechler T, Kosfelder J, Vocks S, Mönninger T, Blankenburg M, Dobe M, Gerlach AL, Denecke H, Zernikow B. Changes in pain-related coping strategies and their importance for treatment outcome following multimodal inpatient treatment: Does sex matter? J Pain. 2010;11(5):472-83.
39. Peng $P$, Choiniere M, Dion D, Intrater H, LeFort S, Lynch M, Ong M, Rashiq S, Tkachuk $G$, Veillette $Y$, et al. Challenges in accessing multidisciplinary pain treatment facilities in Canada. Can J Anaesth. 2007;54(12):985-91.

40. Federal Statistical O. [Information on Health Insurance (Results of the Microcencus]. In., vol. Fachserie 13, Reihe 1.1. Wiesbaden 2012; 2012.

41. Social Code Book V. Social Code Book V - Statutory Health Insurance, §11 Types of Services. http://www.gesetze-im-internet.de/sgb_5 [Accessed 20 Apr 2016].

42. Du Y, Knopf H, Zhuang W, Ellert U. Pain perceived in a national community sample of German children and adolescents. Eur J Pain. 2010;15(6):649-57.

43. Gonzalez A, Boyle MH, Kyu HH, Georgiades K, Duncan L, MacMillan HL. Childhood and family influences on depression, chronic physical conditions, and their comorbidity: findings from the Ontario Child Health Study. Psychiatry Res. 2012;46(11):1475-82.

44. Hoftun GB, Romundstad P, Rygg M. Association of parental chronic pain with chronic pain in the adolescent and young adult. JAMA pediatr. 2013;167(1):61-9.

45. Ensor T, Cooper S. Overcoming barriers to health service access: influencing the demand side. Health Policy Plan. 2004;19(2):69-79.

46. Leung YW, Brual J, Macpherson A, Grace SL. Geographic issues in cardiac rehabilitation utilization: A narrative review. Health Place. 2010;16:1196-205.

47. McLafferty SL. GIS and health care. Annu Rev Public Health. 2003;24(1):25-42.

48. Hradil S. Social inequality in Germany, vol. 8. Wiesbaden: VS Verlag für Sozialwissenschaften; 2001

49. Allin S, Stabile M. Socioeconomic status and child health: What is the role of health care, health conditions, injuries and maternal health? Health Economics. Policy Law. 2012;7(02):227-42.

50. Carlisle CE, Mamdani M, Schachar R, To T. Predictors of psychiatric aftercare among formerly hospitalized adolescents. Can J PsychiatryRev Can Psychol. 2012;57(11):666-76.

51. Wisk LE, Witt WP. Predictors of delayed or forgone needed health care for families with children. Pediatrics. 2012:130(6):1027-37.

52. Nguyen M, Ugarte C, Fuller I, Haas G, Portenoy RK. Access to care for chronic pain: racial and ethnic differences. J Pain. 2005:6(5):301-14.

\section{Submit your next manuscript to BioMed Central and we will help you at every step:}

- We accept pre-submission inquiries

- Our selector tool helps you to find the most relevant journal

- We provide round the clock customer support

- Convenient online submission

- Thorough peer review

- Inclusion in PubMed and all major indexing services

- Maximum visibility for your research

Submit your manuscript at www.biomedcentral.com/submit
) Biomed Central 